\title{
The diversity of hydras (Cnidaria: Hydridae) in the Baikal region
}

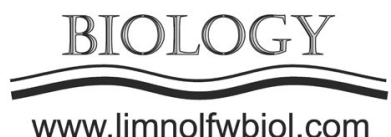

\author{
Peretolchina T.E.*, Khanaev I.V., Kravtsova L.S. \\ Limnological Institute, Siberian Branch of the Russian Academy of Sciences, Ulan-Batorskaya Str., 3, Irkutsk, 664033, Russia
}

\begin{abstract}
We have studied the fauna of Hydra in the waters of the Baikal region using morphological and molecular genetic methods. By the external morphological features of the structure of the polyp and the microscopic study of nematocysts, we have identified four species belonging to three different genetic groups: "oligactis group" (Hydra oligactis, H. oxycnida), "braueri group" (H. circumcincta) and "vulgaris group" (H. vulgaris). Molecular phylogenetic analysis has confirmed the species status of the hydras studied. The intraspecific genetic distances between the Baikal and European hydras are 1.5$4.2 \%$ and $0.4-2.7 \%$ of the substitutions in COI and ITS1-5.8S-ITS2 markers, respectively, while, interspecific distances for different species significantly exceed intraspecific and amount to $9.8-16.1 \%$ and $6.4-32.1 \%$ of substitutions for the markers COI and ITS1-5.8S-ITS2, respectively. The temperature regime of the water and the availability of food resources, which play a key role in the reproduction of hydras, determine the habitats of the identified species. The research performed has replenished the regional fauna with species whose findings were previously considered presumptive or doubtful. The first record of $H$. vulgaris in the artificial reservoir near the Angara River (Lake Kuzmikhinskoye) will help to clarify the distribution of this species.
\end{abstract}

Keywords: Baikal region, Hydra, nematocysts, molecular phylogenetic analysis

\section{Introduction}

Hydra is a member of the ancient phylum Cnidaria, class Hydrozoa, order Hydroida, family Hydridae. Genus Hydra comprises 15 species (Jankowski et al., 2008), five of them are found in Europe: Hydra viridissima Pallas, 1766, H. circumcincta Schulze, 1914, $H$. oligactis Pallas, 1766, H. vulgaris Pallas, 1766 and $H$. oxycnida Schulze, 1914 (Schuchert, 2010).

There have been no detailed studies of the fauna of the cnidarians in Lake Baikal. According to available literature data, four species of freshwater hydroids of the genus Hydra were recorded in Lake Baikal: $H$. baikalensis, $H$. oligactis and, rarely, $H$. circumcincta, $H$. oxycnida $(=H$. oxycnidoides sensu Shultze, 1927) (Kozhov, 1962; Stepanyants et al., 2003; 2006). Gajewskaja supposed the existence of $H$. vulgaris in Lake Baikal (Gajewskaja, 1933); however, subsequent researchers never found $H$. vulgaris, as well as $H$. oxycnida, and doubted their presence in the lake. In the "Index of animal species inhabiting Lake Baikal and its catchment area", only two species are mentioned: $H$. oligactis and $H$. baikalensis (Stepanyants and Anokhin, 2001).

The aim of this work was to study the diversity of the fauna of the hydroids in the Baikal region using morphological and molecular genetic methods.

\section{Materials and methods}

Hydras were collected at depths of 1 to 18 meters by a scuba diver and with hands: 1) along the littoral zone of Lake Baikal; 2) in Posolsky Sor. Hydras together with aquatic plants were also collected by hands from lakes Zama (near Lake Baikal) and Kuzmikhinskoye (the artificial reservoir near the Angara River) at depths of $0.5 \mathrm{~m}$ (Fig. 1). Typically, representatives of Hydra were brought live to the laboratory, but some samples were fixed in $80 \%$ ethanol in the field.

The nematocysts of Hydra representatives (stenoteles, desmonemes holotrichous and atrichous isorhizas) were photographed using Olympus CX22 microscope with 1000-fold magnification under oil immersion. Morphometric measurements of holotrichous isorhizas and stenoteles were carried out with the Image-Pro program (Table 1). Hydras specimens were identified according to keys provided by Schuchert (2010) and Anokhin (2002).

DNA was extracted from a single live or fixed specimen according to the protocol described by Doyle and Dickson (1987). Gene fragments of mitochondrial cytochrome c oxidase subunit I (COI) and internal transcribed spacer 1 - 5.8S ribosomal DNA - internal transcribed spacer 2 (ITS1-5.8S-ITS2) were amplified in PCR using the primers listed in Table 2. The PCR 


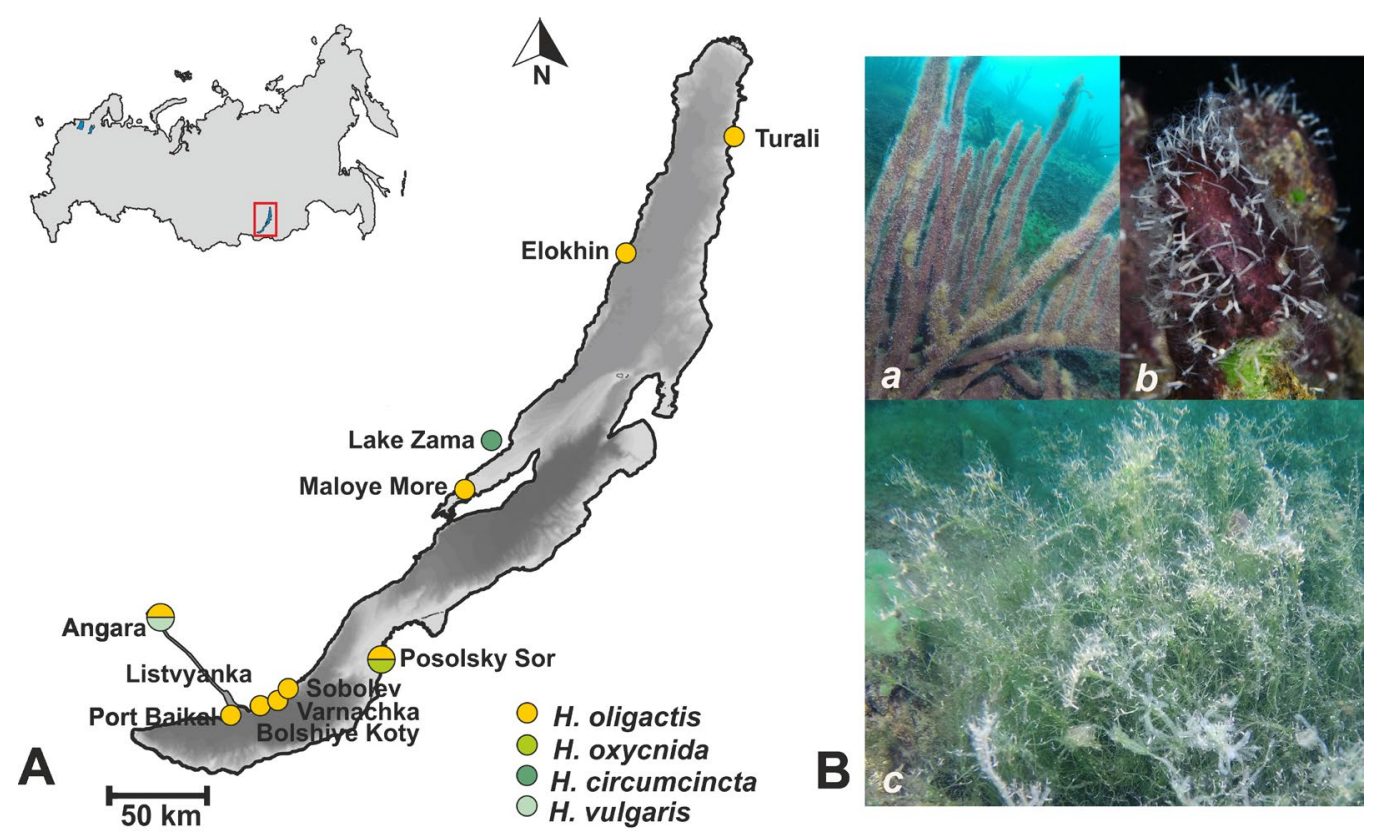

Fig. 1. A - Sampling sites of Hydra; B - photos of massively growing H. oligactis on the dying Porifera $(a, b)$ and on the filamentous algae (c) (photos by I.V. Khanaev)

amplification conditions for both molecular markers were as follows: denaturation at $94{ }^{\circ} \mathrm{C}$ for $5 \mathrm{~min}, 30$ cycles at $94{ }^{\circ} \mathrm{C}$ for $30 \mathrm{sec}, 50{ }^{\circ} \mathrm{C}$ for $45 \mathrm{sec}, 72{ }^{\circ} \mathrm{C}$ for $2 \mathrm{~min}$, and a final elongation step at $72^{\circ} \mathrm{C}$ for $10 \mathrm{~min}$. Direct sequencing of forward sequences was performed in Research and Production Company SYNTOL (Russia) using an ABI 3130 automated sequencer.

The DNA sequences obtained were edited in BioEdit v.7.2.5 (Hall, 2011) and aligned using ClustalW (Thompson et al., 1994) and MAFFT v.6.240 (Katoh et al., 2002). Resulting COI alignment was translated to check for the absence of stop codons. To confirm species identity, we compared our sequence dataset with the published ortholog sequences from other members of Hydra and analyzed genetic distances using Mega v.6 (Table 3) (Tamura et al., 2013).

Phylogenetic analysis was performed using MrBayes v.3.2 (Ronquist and Huelsenbeck, 2003). The dataset consisted of eight combined COI + ITS15.8S-ITS2 sequences: four sequences of hydra specimens produced for this study and four ones of specimens belonging to European species: $H$. circumcincta (GU722853, GU722669), H. oligactis (GU722868, GU722691), H. vulgaris (GU722918, GU722744) and H. oxycnida (GU722876, GU722690) (Martínez et al., 2010) retrieved from GenBank. To estimate the poste- rior probabilities of the phylogenetic tree, we used 15,000,000 generations of Metropolis-coupled Markov chain Monte Carlo simulation (two runs with four chains). We used the jModelTest v.2.1 (Darriba et al., 2012) to determine the substitution models for the three genes separately. The best-fit model for phylogenetic analysis in each case was GTR $+\mathrm{I}+\mathrm{G}$. We constructed a majority-rule (50\%) consensus tree following $25 \%$ burn-in of all sampled trees to allow likelihood values to reach stationary equilibrium.

\section{Results and discussion}

All Hydra samples collected were identified by external morphology of polyps and microscopic examination of their nematocysts as $H$. oligactis, $H$. oxycnida ("oligactis group"), $H$. circumcincta ("braueri group") and $H$. vulgaris ("vulgaris group") (Fig. 2).

The consensus tree topology (Fig. 3) based on combined sequence data (COI and ITS1-5.8S-ITS2) have confirmed that hydras from the Baikal region belong to four species: $H$. circumcincta, $H$. oligactis, $H$. vulgaris and $H$. oxycnida. The intra-specific distances of hydras from the Baikal region and Europe do not exceed $5 \%$ that indicate species level of the samples studied (Martínez et al., 2010; Schwentner and Bosch,

Table 1. The nematocysts sizes of different species of Hydra from the Baikal region

\begin{tabular}{|c|c|c|c|c|c|c|c|c|c|c|c|c|c|c|}
\hline \multirow[t]{3}{*}{ Species } & \multicolumn{7}{|c|}{ holotrichous isorhiza } & \multicolumn{7}{|c|}{ stenotele } \\
\hline & \multicolumn{3}{|c|}{ width, $\mu \mathrm{m}$} & \multicolumn{3}{|c|}{ length, $\mu \mathrm{m}$} & \multirow[t]{2}{*}{$\mathrm{n}$} & \multicolumn{3}{|c|}{ width, $\mu \mathrm{m}$} & \multicolumn{3}{|c|}{ length, $\mu \mathrm{m}$} & \multirow[t]{2}{*}{$\mathrm{n}$} \\
\hline & $\mathrm{x} \pm \mathrm{m}$ & $\min$ & $\max$ & $\mathrm{x} \pm \mathrm{m}$ & $\min$ & $\max$ & & $\mathrm{x} \pm \mathrm{m}$ & $\min$ & $\max$ & $\mathrm{x} \pm \mathrm{m}$ & $\min$ & $\max$ & \\
\hline H. oligactis & $4.2 \pm<0.1$ & 3.1 & 5.2 & $8.8 \pm 0.1$ & 7.4 & 11.4 & 100 & $9.6 \pm 0.1$ & 9.1 & 9.9 & $12.9 \pm 0.2$ & 12.2 & 13.6 & 8 \\
\hline H. oxycnida & $4.2 \pm 0.1$ & 3.9 & 4.8 & $10.1 \pm 0.2$ & 8.9 & 11.4 & 15 & $11.8 \pm 0.2$ & 10.7 & 12.8 & $20.3 \pm 0.5$ & 18.0 & 22.8 & 9 \\
\hline H. circumcincta & $5.8 \pm 0.1$ & 4.9 & 6.7 & $8.6 \pm 0.1$ & 7.5 & 9.4 & 29 & $11.6 \pm 0.5$ & 10.6 & 12.6 & $13.6 \pm<0.1$ & 13.5 & 13.6 & 3 \\
\hline H. vulgaris & $4.7 \pm 0.1$ & 4.2 & 5.2 & $10.2 \pm 0.2$ & 7.9 & 12.4 & 19 & $12.6 \pm 2.2$ & 9.9 & 25.6 & $16.4 \pm 2.6$ & 11.6 & 31.9 & 7 \\
\hline
\end{tabular}

$\mathrm{x}$ - mean, $\mathrm{m}$ - standard error of mean, min and max - limits, $\mathrm{n}$ - number of measurements 
Table 2. Primers used in this study

\begin{tabular}{|l|l|l|}
\hline \multicolumn{1}{|c|}{ Gene } & \multicolumn{1}{|c|}{ Primer } & \multicolumn{1}{c|}{ Reference } \\
\hline COI & $\begin{array}{l}|c| \\
\text { LCO1490: 5'-GGT CAA CAA ATC ATA AAG ATA TTG G-3' } \\
\text { HCO2198: 5'-TAA ACT TCA GGG TGA CCA AAA AAT CA-3' }\end{array}$ & Folmer et al. (1994) \\
ITS1-5.8S-ITS2 & $\begin{array}{l}\text { ITS1 (f): 5'-TCC GTA GGT GAA CCT GCG G-3' } \\
\text { ITS4 (r): 5'- TCC TCC GCT TAT TGA TAT GC-3 }\end{array}$ & White et al. (1990) \\
\hline
\end{tabular}

2015). Inter-specific distances varied from $9.8 \%$ to $16.1 \%$ between COI sequences and from $6.4 \%$ to $32.1 \%$ between ITS1-5.8S-ITS2 sequences for different species of Hydra (Table 3). Large genetic distances between hydras belonging to different genetic groups determined by ITS1-5.8S-ITS2 marker can be explained by presence of indels obtained after alignment.

Below are the ecological and morphological characteristics of the studied species (the description of the species based on morphological characters according to Schuchert (2010) and measurements of nematocysts (Table 1)):

Phylum Cnidaria Verrill, 1865

Subphylum Medusozoa Peterson, 1979

Class Hydrozoa Owen, 1843

Subclass Hydroidolina Collins 2000

Order Anthoathecata Cornelius, 1992

Family Hydridae Dana, 1846

Hydra oligactis Pallas, 1766, syn.: Hydra fusca Linnaeus, Hydra roeselii Haacke, Hydra rhaetica Asper, Hydra rhistica Asper, Pelmatohydra oligactis Schulze.

Description. The Baikal Hydra is large, typically with 5-7 long tentacles and a more or less distinct pedicel. The cnidome includes four types of nematocysts: stenoteles, holotrichous isorhizas, atrichous isorhizas and desmonemes (Fig. 2E-H). Holotrichous isorhizas are elongated, with a length/width ratio of approximately 2 , and with thread-forming longitudinal irregular coils inside the capsule. Other types of nematocysts are of a size and shape typical of hydras. Sexes are strictly separated, no sex change, the onset of gametogenesis stops vegetative budding.

Distribution. Lake Baikal: Port Baikal, Ulanovo, Listvennichny Bay, Bolshie Koty, Varnachka, Sobolev Cape, Turali Cape, Elokhin Cape, Mukhor Bay, Posolsky Sor; Lake Kuzmikhinskoye (Artificial reservoir near the Angara River). This species is also widespread and common on the entire European continent, including the British Isles and Iceland as well as Russia and North
America (Hyman, 1930; Holstein, 1995; Stepanyants et al., 2006).

Hydra oxycnida Schulze, 1914, syn.: Hydra oxycnidoides Schulze, 1927, Hydra pirardi Brien, 1961.

Description. Very large dark brown Hydra without pedicel, stenoteles are markedly ovoid (Fig 2D), width/ length ratio is 0.6 , and upper part is characteristically pointed. Holotrichous isorhizas are ovoid to oval, the length/width ratio is $>2$ (Fig. 2B), there is shaft in intact capsule thread in 3-4 oblique or transverse coils in the upper part of capsule. Tentacles are 7-8, rarely $6-11$, relatively short, extended and reaching only $1 / 4$ to $1 / 3$ of body length, polyp buds form tentacles simultaneously. Sexes are strictly separated, no sex change, the onset of gametogenesis stops vegetative budding and nematocyst production.

Distribution. Lake Baikal (Posolsky Sor). Additionally, it occurs in Russia (Holstein, 1995) and is common in Northern Europe (Schuchert, 2010).

Hydra circumcincta Schulze, 1914, syn.: Hydra braueri Bedot, 1912, Hydra stellata Schulze, 1914, Hydra ovata Boecker, 1920, Hydra graysoni.

Description. Small Hydra with short tentacles, no pedicel, holotrichous isorhizas are ovoid (Fig. 2K), the length/width ratio is $<1.5$, there is thread in 3-4 distinct coils in the upper part of capsule, stenoteles are ovoid (Fig. 2L), with two size classes, the width/length ratio is approximately 0.85 . Hypostome is conical, below hypostome there are usually six tentacles, sometimes five tentacles, tentacles are shorter than hydranth body (ratio < 0.5), held horizontally. Contracted hydranths are with star-shaped tentacle crown. Vegetative multiplication is by buds, which are relatively basal, tentacles of buds are formed simultaneously, usually six in number. Vegetative and sexual reproduction can occur simultaneously. Sexual reproduction is as hermaphrodites, sometimes proterandric.

Distribution. Lake Zama (near Lake Baikal). They are also found in Russia, Japan, North America

Table 3. Pairwise $p$-distances between COI (below diagonal) and ITS1-5.8S-ITS2 (above diagonal) for different species of Hydra. Intra-specific pairwise $p$-distances are in bold.

\begin{tabular}{|l|c|c|c|c|}
\hline & H. oxycnida & H. oligactis & H. vulgaris & H. circumcincta \\
\hline H. oxycnida & $\mathbf{0 . 0 1 5 ( 0 . 0 0 4 )}$ & 0.064 & 0.205 & 0.317 \\
H. oligactis & 0.098 & $\mathbf{0 . 0 1 8 ( 0 , 0 0 7 )}$ & 0.214 & 0.321 \\
H. vulgaris & 0.123 & 0.122 & $\mathbf{0 . 0 4 2}(\mathbf{0 . 0 2 6})$ & 0.251 \\
H. circumcincta & 0.161 & 0.158 & 0.132 & $\mathbf{0 . 0 3 6 ( 0 . 0 2 7 )}$ \\
\hline
\end{tabular}




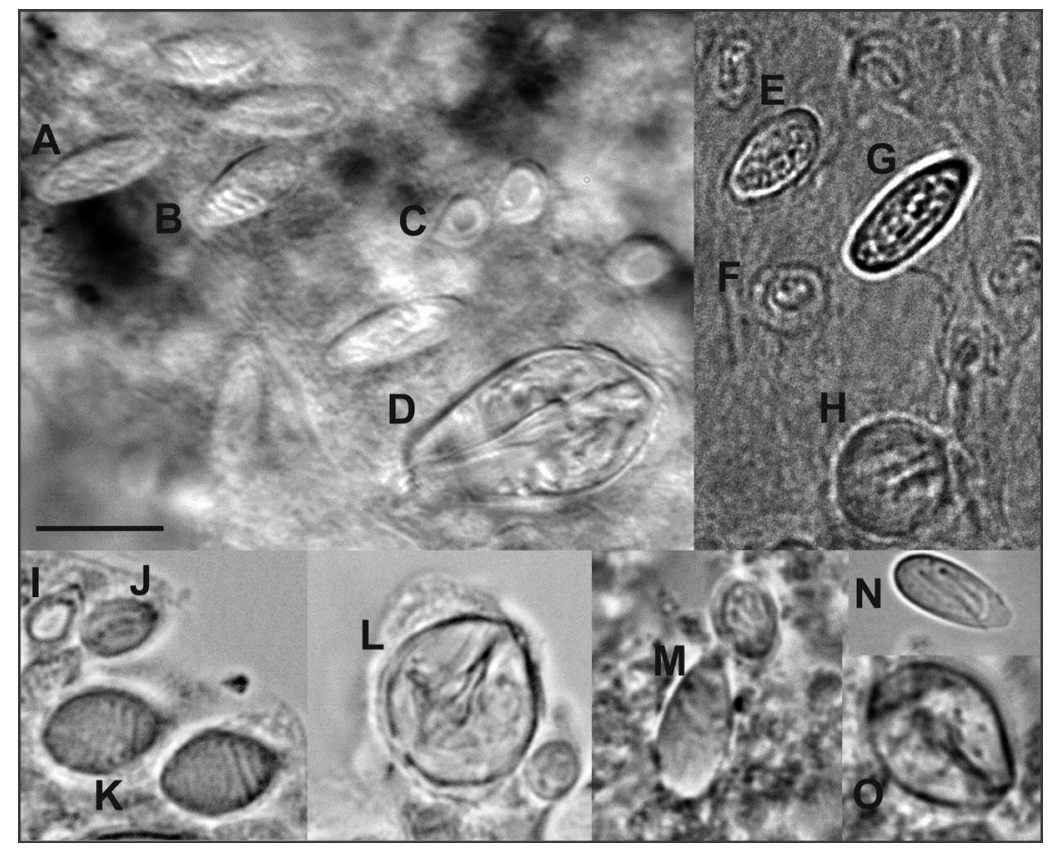

Fig. 2. Nematocysts of different Hydra species: A-D - H. oxycnida; E-H - H. oligactis; I-L - H. circumcincta; M-O - H. vulgaris. A, E, J, N - atrichous isorhizas; C, F, I - desmonemes; B, G, K, M - holotrichous isorhizas; D, H, L, O - stenoteles. Scale bar is $10 \mu \mathrm{m}$.

(Heitkamp, 1986; Holstein, 1995; Stepanyants et al., 2006) and in Europe, including the British Isles, except for Iceland (Schuchert, 2010).

Hydra vulgaris Pallas, 1766, syn.: Hydra grisea Linnaeus, 1767, Hydra vulgaris aurantiaca Ehrenberg, 1838, Hydra trembleyi Haacke, 1879.

Description. Medium sized Hydra, extended hydranth is usually 3-6 mm, may reach sizes of up to $15 \mathrm{~mm}$, with 6-8 long tentacles, without algal symbionts, no or indistinct pedicel, holotrichous isorhizas are oblong, the length/width ratio is $>2$, thread is in 4-5 oblique or transverse coils the in upper part of capsule, stenotele width/length ratio is approximately 0.78 (Fig. 2M, O). Vegetative multiplication is by buds located in lower third of the body, usually there are only 1-2 buds, rarely 3-4, initial four tentacles of buds are formed more or less simultaneously, later more tentacles develop, and, thus, tentacles are transiently of unequal length. Vegetative and sexual reproduction can occur simultaneously. Sexual reproduction of gonochoristic and hermaphroditic animals is very rare. In hermaphrodites, male and female gonads are mixed, and are not in separate regions.

Distribution. Lake Kuzmikhinskoye (Artificial reservoir near the Angara River). In Russia, it was found in the Far East (Stepanyants et al., 2006). It also inhabits the entire European continent and the British Isles (Schuchert, 2010).

Currently, among the hydras listed above, in open Lake Baikal only $H$. oligactis occurs, mass growth of which has been observed in the last decade (Fig. 1B). Representatives of this species are capable of very intense budding: 10-20 young polyps that have not yet budded are found on one maternal specimen (Stepanyants et al., 2003; Tökölyi et al., 2016). For this reason, $H$. oligactis became the most widespread repre-

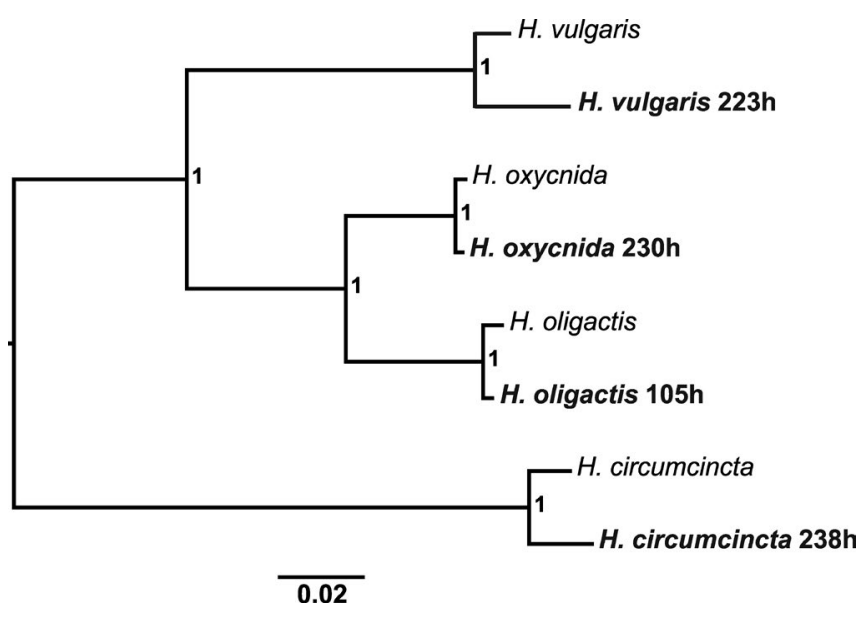

Fig. 3. Combined COI and ITS1-5.8S-ITS2 phylogenetic tree. Haplotypes of hydras from the Baikal region are in bold

sentative of freshwater cnidaria in almost all continental waters. Previously, representatives of hydras were found in small numbers in the coastal zone of Lake Baikal. The first record of the mass development of $H$. oligactis was in the 2000s (Stepanyants et al., 2003). Now, it is abundant along the open coasts of all three basins of Lake Baikal. In the last decade, the blooming of filamentous algae (Spirogyra, Ulotrix and others) and the trend towards a more widespread distribution of invasive species, in particular, Elodea canadensis, have been observed in Lake Baikal (Kravtsova et al., 2010). In addition, mass death of the endemic species of Porifera (Denikina et al., 2016; Khanaev et al., 2018) is currently observed. On the contrary, representatives of Hydra acquire a significant role along the open coasts of Lake Baikal.

According to the literature data, the temperature optimum for sexual reproduction of $H$. oligactis is 10-12 
${ }^{\circ} \mathrm{C}$, and for vegetative budding is $18-22{ }^{\circ} \mathrm{C}$ (Littlefield, 1991). The water temperature in the surface layer of the coastal zone of the Lake Baikal in summer does not exceed $16{ }^{\circ} \mathrm{C}$ (Timoshkin et al., 2018). Despite the fact that the water temperature in Baikal is slightly lower than the temperature optimum for vegetative reproduction, $H$. oligactis exhibits intensive budding and develops along the open coasts of the lake in all three basins.

Due to the global climate change since the early 70s of the past century, an increase in air temperature has been observed in the Baikal region during all seasons of the year, especially in winter, as well as an increase in the duration of the ice-free period of Lake Baikal and warming of its surface waters (in May-September) by 1 ${ }^{\circ} \mathrm{C}$ (Shimaraev et al., 2002). However, such increase in temperature hardly contributes to the mass distribution of other Hydra species in open Baikal, in particular, $H$. oxycnida, $H$. circumcincta and $H$. vulgaris.

Rare species $H$. oxycnida was found in 2015 together with $H$. oligactis on the leaves of Potamogeton perfoliatus in the coastal zone of Lake Baikal, Posolsky Sor, where the temperature of water during the summer may reach $24^{\circ} \mathrm{C}$ (Kozhov, 1947). Despite the existing water exchange between Posolsky Sor and open Baikal, $H$. oxycnida has not been observed yet outside this area, unlike $H$. oligactis. Perhaps, the rare records of $H$. oxycnida, even in the coastal zone, are due to not only environmental conditions but also the biological features of this species, which are the lower rate of budding during the vegetative reproduction than in $H$. oligactis (Schuhert, 2010).

The habitats of other representatives of Hydra are confined to shallow water bodies located in areas adjacent to Lake Baikal. $H$. circumcincta lives in Lake Zama near Lake Baikal. The maximum depth of Zama is $1.5 \mathrm{~m}$ (average is $1 \mathrm{~m}$ ); bottom sediments are sand with detritus and pebble covered with silt. The water in the lake is yellowish; the temperature in August is 18.4 ${ }^{\circ} \mathrm{C}$. There are thickets of Potamogeton and Ceratophylum; Copepoda $\left(77,000\right.$ specimens $\left./ \mathrm{m}^{2}\right)$, Rotatoria $(52,000$ specimens $/ \mathrm{m}^{2}$ ) and Cladocera (20,000 specimens/ $\mathrm{m}^{2}$ ) dominate in zooplankton (Koryakov et al., 1977). The abundance of food for hydras is also an important factor influencing the biological characteristics of the species as well as temperature. The availability of food resources plays a key role in the change of the reproduction strategy of hydras (Kaliszewicz and Lipinska, 2013).

In 2018, $H$. vulgaris was found in the Baikal region for the first time in Lake Kuzmikhinskoye located near the Angara River, downstream dam. This is an artificial reservoir created during the construction of the Irkutsk Hydroelectric Power Station in 1950. The lake has a length of $430 \mathrm{~m}$, a width of $145 \mathrm{~m}$ and a maximum depth of 2.7 m (Kamaltynov and Kamaltynov, 2000). Bottom sediments in the lake consist of silted sand with pebbles and plant detritus; occasionally fragments of marble rocks are found. The summer water temperature in the lake is over $20{ }^{\circ} \mathrm{C}$. Elodea canadensis dominates among the aquatic plants. Apparently, the temperature regime in Lake Kuzmihinskoye corresponds to those in the water bodies of Europe and the Far East.

\section{Conclusions}

Thus, in the Baikal region, the fauna of hydras is represented by typical inhabitants of freshwater bodies of northern latitudes. The morphological and molecular genetic analysis of the hydras from the Baikal region water bodies studied allowed us to uniquely identify four species: $H$. oligactis, $H$. oxycnida, $H$. circumcincta and $H$. vulgaris. In open part and in the coastal zone of Lake Baikal, only representatives of the "oligactis group" were found: $H$. oligactis and $H$. oxycnida. The regional fauna of the hydra has been replenished with species whose findings were previously considered presumptive or doubtful. The record of $H$. vulgaris in the Baikal region makes the species area less fragmented since it was previously found only in water bodies of Europe and the Far East.

\section{Acknowledgements}

We thank Dr. Tatiana Y. Sitnikova, Ivan A. Nebesnykh and Yuriy A. Yuschuk for their assistance in collecting material. This study was supported by the governmentally funded project No. 0345-2016-0004 (AAAA-A16-116122110060-9).

\section{References}

Adams J., Greenwood P. J., Naylor C.J. 1987. Evolutionary aspects of environmental sex determination. International Journal of Invertebrate Reproduction and Development 11: 123-136. DOI: 10/1080/01688170.1987.10510273.

Anokhin B. 2002. Redescription of the endemic Baikalian species Pelmatohydra baikalensis (Cnidaria: Hydrozoa, Hidridae) and assessment of the hydra fauna of Lake Baikal. Annales zoologici 52: 195-200.

Darriba D., Taboada G.L., Doallo R. et al. 2012. jModelTest 2: more models, new heuristics and parallel computing. Nature methods 9: 772. DOI: 10.1038/nmeth.2109

Denikina N.N., Dzyuba E.V., Bel'kova N.L. et al. 2016. The first case of disease of the sponge Lubomirskia baicalensis: investigation of its microbiome. Biology Bulletin 43: 263-270. DOI: 10.1134/S106235901603002X

Doyle J.J., Dickson E. 1987. Preservation of plant samples for DNA restriction endonuclease analysis. Taxon 36: 715-722.

Folmer O., Black M., Hoeh W. et al. 1994. DNA primers for amplification of mitochondrial cytochrome c oxidase subunit I from diverse metazoan invertebrates. Molecular Marine Biology and Biotechnology 3: 294-299.

Gajewskaja N. 1933. Ecology, morphology and systematics of the infusoria of Lake Baikal. Zoologica 85: 1-29. (In German)

Hall T. 2011. BioEdit: an important software for molecular biology. Green Earth Research Foundation Bulletin of Bioscience 2: 60-61.

Holstein T. 1995. Cnidaria: Hydrozoa. In: Schwoerbel J. and Zwick P. (Eds.), Freshwater fauna of Central Europe, Cnidaria: Hydrozoa / Kamptozoa. Stuttgart, pp. 1-142. (In German)

Hyman L. H. 1930. Taxonomic studies on the Hydra of North America. II. The characters of Pelmatohydra oligactis Pallas. Transactions of the American microscopical Society 
49: 322-333. DOI: $10.2307 / 3222161$

Jankowski T., Collins A.G., Campbell R.D. 2008. Global diversity of inland water cnidarians. Hydrobiology 595: 35-40. DOI: 10.1007/s10750-007-9001-9

Kaliszewicz A., Lipińska A. 2013. Environmental condition related reproductive strategies and sex ratio in hydras. Acta Zoologica (Stockholm) 94: 177-183. DOI: 10.1111/j.1463-6395.2011.00536.x

Kamaltynov R.M., Kamaltynov P.R. 2000. Crawfish colonization of the basins near Irkutsk City. In: Third International Vereshchagin Baikal Conference, pp. 103.

Katoh K., Misawa K., Kuma K. et al. 2002. MAFFT: A novel method for rapid multiple sequence alignment based on fast Fourier transform. Nucleic Acids Research 30: 3059-3066.

Khanaev I.V., Kravtsova L.S., Maikova O.O. et al. 2018. Current state of the sponge fauna (Porifera: Lubomirskiidae) of Lake Baikal: Sponge disease and the problem of conservation of diversity. Journal of Great Lakes Research 44: 77-85. DOI: $10.1016 /$ j.jglr.2017.10.004

Koryakov E.A., Glazunov I.V., Vilisova I.K. 1977. Coastal lakes of Lake Baikal until its stabilization. In: Florensov N.A. (Ed.), Limnology of the coastal zone of Lake Baikal. Novosibirsk, pp. 4-44. (in Russian)

Kozhov M.M. 1947. The animal world of Lake Baikal. Irkutsk: Ogiz. (in Russian)

Kozhov M.M. 1962. Biology of Lake Baikal. Moscow: Nauka. (in Russian)

Kravtsova L.S., Izhboldina L.A., Mekhanikiva I.V. et al. 2010. Naturalization of Elodea canadensis Mich. in Lake Baikal. Russian Journal of Biological Invasions 1: 162-171. DOI: 10.1134/S2075111710030045 (in Russian)

Littlefield C.L. 1986. Sex determination in hydra: control by a subpopulation of interstitial cells in Hydra oligactis males. Developmental Biology 117: 428-434.

Martínez D.E., Iñigues A.R., Percell K.M. et al. 2010. Phylogeny and biogeography of Hydra (Cnidaria: Hydridae) using mitochondrial and nuclear DNA sequences. Molecular Phylogenetics and Evolution 57: 403-410. DOI: 10.1016/j. ympev.2010.06.016

Ronquist F., Huelsenbeck J.P. 2003. MrBayes 3: Bayesian phylogenetic inference under mixed models. Bioinformatics 19: 1572-1574. DOI: 10.1093/bioinformatics/btg180.

Schuchert P. 2010. The European athecate hydroids and their medusae (Hydrozoa, Cnidaria): Capitata part 2. Revue suisse de Zoologie 3: 440-449.

Schwentner M., Bosch T.C.G. 2015. Revisiting the age, evolutionary history and species level diversity of the genus Hydra (Cnidaria: Hydridae). Molecular Phylogenetics and Evolution 91: 41-55. DOI: 10.1016/j.ympev.2015.05.013

Shimaraev M.N., Kuimova L.N., Sinyukovich V.N. 2002. On evidence of global climate changes at Lake Baikal in the XX century. Doklady Earth Science 383: 397-400.

Stepanyants S.D., Anokhin B.A. 2001. Hydrozoa (Cnidaria: Hydrida). In: Timoshkin O.A. (Ed.), Index of animal species inhabiting Lake Baikal and its catchment area. Volume 1, Book 1. Novosibirsk, pp. 193-194. (in Russian)

Stepanyants S.D., Kuznetsova V.G., Anokhin B.A. 2003. Hydra: from Abraam Tramble until our days. MoscowSaint-Petersburg: Association of scientific publications KMK. (in Russian)

Stepanyants S.D., Anokhin B.A., Kuznetsova V.G. 2006. Cnidarian fauna of relict Lakes Baikal, Biwa and Khubsugul. Hidrobiologia 568: 225-232. DOI: 10.1007/ s10750-006-0310-1

Tamura K., Stecher G., Peterson D. et al. 2013. MEGA6: molecular evolutionary genetics analysis version 6.0. Molecular Biology and Evolution 30: 2725-2729. DOI: 10.1093/molbev/mst197

Thompson J.D., Higgins D.G., Gibson T.J. 1994. ClustalW: improving the sensitivity of progressive multiple sequence alignment through sequence weighting, positionspecific gap penalties and weight matrix choice. Nucleic Acids Research 22: 4673-4680.

Timoshkin O.A., Moore M.V., Kulikova N.N. et al. 2018. Groundwater contamination by sewage causes benthic algal outbreaks in the littoral zone of Lake Baikal (East Siberia). Journal of Great Lakes Research 44: 230-244. DOI: 10.1016/j. jglr.2018.01.008

Tökölyi J., Bradács F., Hóka N. et al. 2016. Effects of food availability on asexual reproduction and stress tolerance along the fast-slow life history continuum in freshwater hydra (Cnidaria: Hydrozoa). Hydrobiologia 766: 121-133.

White T.J., Bruns T., Lee S. et al. 1990. Amplification and direct sequencing of fungal ribosomal RNA genes for phylogenetics. In: Innis M.A., Gelfand D.H., Sninsky J.J., White T.J. (Eds.), PCR Protocols: A Guide to Methods and Applications. NY Acad. Press, pp. 315-322. 